\title{
TANTANGAN INDUSTRI CAT DALAM NEGERI DALAM MENGHADAPI GLOBAL LEAD PAINT ELIMINATION BY 2020
}

\author{
CHALLENGE OF NATIONAL PAINT INDUSTRY FOR FACING GLOBAL LEAD \\ PAINT ELIMINATION BY 2020
}

\author{
Deni Cahyadi, Daniel Fajar Puspita, Wieke Pratiwi
}

Balai Besar Bahan dan Barang Teknik, Jl. Sangkuriang No.14, Bandung

Email: ajeungan@gmail.com

Diterima: 15 September 2015
Direvisi: 17 November 2015
Disetujui: 14 Desember 2015

\begin{abstract}
ABSTRAK
Kajian ini menjelaskan mengenai perkembangan kandungan timbal dalam cat, kesiapan industri lokal, dan beberapa langkah strategis dan teknis yang dapat dilakukan oleh pihak terkait untuk menghadapi rencana penghilangan kandungan timbal pada produk cat pada tahun 2020. Pengujian beberapa produk cat yang dipasarkan di Indonesia pada Agustus 2015, menunjukkan bahwa cat tembok waterbased mengandung timbal antara 10-48 $\mathrm{mg} / \mathrm{kg}$, cat enamel memiliki kandungan timbal pada kisaran $616-2254 \mathrm{mg} / \mathrm{kg}$, cat marka jalan jenis oilbased mengandung timbal kira-kira $5876 \mathrm{mg} / \mathrm{kg}$, cat antifouling sebesar $27 \mathrm{mg} / \mathrm{kg}$, dan cat alkyd untuk keperluan protective coatings sebesar $50 \mathrm{mg} / \mathrm{kg}$. Beberapa industri cat besar sudah mampu menghasilkan produk cat dengan kandungan timbal di bawah $90 \mathrm{mg} / \mathrm{kg}$ dan mencantumkan label lead free pada kemasan produknya. Tetapi industri cat menengah dan kecil belum memproduksi cat dengan kandungan timbal di bawah $90 \mathrm{mg} / \mathrm{kg}$. Karena itu untuk menyongsong program global kandungan timbal di bawah $90 \mathrm{mg} / \mathrm{kg}$ menuju tahun 2020, pemerintah harus segera melakukan pembenahan regulasi teknis, revisi SNI, sosialisasi dan publikasi ilmiah, serta meningkatkan penelitian dan pengembangan bahan pengganti timbal. Pelatihan dan pendampingan teknis mungkin juga perlu dilakukan kepada Industri Kecil dan Menengah (IKM).
\end{abstract}

Kata kunci: cat, timbal, regulasi

\section{ABSTRACT}

This study dealt with global development of lead content in paints product, local industries readiness, and some possible strategic and technical steps for facing the Global Lead Paint Elimination Programme (GAELP) by 2020. Analysis of lead content in several paints in Indonesian market in August 2015 showed that the lead content in paints were as follows: waterbased paints in the range of 10-48 mg/kg, enamel decoration paints $616-2254 \mathrm{mg} / \mathrm{kg}$, oilbased roadmarking paint $5876 \mathrm{mg} / \mathrm{kg}$, antifouling paints $27 \mathrm{mg} / \mathrm{kg}$, and alkyd protective paint $50 \mathrm{mg} / \mathrm{kg}$. Some big paint industries usually have produced paints with lead content below $90 \mathrm{mg} / \mathrm{kg}$ or even declare a lead free label. However most middle and small paint industries do not yet produce any lead free paints. Therefore to face Global Lead Paint Elimination by 2020, it is necessary to revise the technical regulation, Indonesian National Standard (SNI), conduct dissemination and publication, also enhance research and development on lead substitute material. Training and technical assistance may be also needed for Small and Medium Enterprise (SME).

Keywords: paints, lead, regulation

\section{PENDAHULUAN}

Kandungan timbal yang terkandung dalam berbagai jenis cat yang beredar di masyarakat menjadi isu yang cukup hangat pada tahun 2014 di tanah air. Menurut salah satu lembaga yang melakukan penelitian mandiri terhadap kandungan timbal dalam cat pada tahun 2013, ditemukan sebanyak $77 \%$ dari 78 sampel cat yang beredar mengandung timbal $>90 \mathrm{ppm}$, dengan kandungan timbal rata-rata dari keseluruhan sampel mencapai 17.300 ppm [1]. Pada tahun 2015 ditemukan sebanyak 83\% dari contoh cat yang beredar mengandung timbal $>90$ ppm [15].

Timbal dapat menyebabkan gangguan kesehatan tanpa memandang usia dengan resiko terbesar pada anak-anak yang dapat meng- 
akibatkan gangguan perkembangan sistem syaraf, pada ibu hamil dapat menularkan timbal ke bayi yang dikandungnya, dan keracunan timbal pada umumnya dapat mengakibatkan gangguan fungsi ginjal, keguguran, kesuburan dan gangguan fungsi organ tubuh lainnya [2].

Pada tahun 2012, IPEN (International POPs Elimination Network) membuat program untuk menghabiskan (phasing out) penggunaan bahan baku yang mengandung timbal pada produk cat [3]. Bekerjasama dengan Badan PBB untuk kesehatan dunia WHO dan lembaga lainnya untuk mendorong terwujudnya cat bebas timbal (lead free paint) secara global pada tahun 2020, termasuk di Indonesia.

Tuntutan global terkait penghilangan (phase out) kandungan timbal dalam komoditi cat tentu tidak bisa dihindari oleh seluruh stake holder industri cat dalam negeri. Dukungan dari pihak pemerintah selaku pemegang kebijakan, pihak industri selaku pelaku usaha, dan masyarakat atau industri pengguna selaku konsumen mutlak diperlukan supaya industri nasional dapat bersaing dan tidak dirugikan dengan menjadi lokasi produksi ataupun konsumsi cat yang berpotensi membahayakan kesehatan dan tidak ramah lingkungan akibat terlambat mengikuti perkembangan industri internasional.

Perkembangan program penghilangan timbal pada produk cat (lead free paint) telah terlebih dahulu dilaksanakan di negara maju dan beberapa negara berkembang baik di Asia maupun di Afrika.

Tabel 1. Program Penghapusan Timbal dalam Cat di Asia

\begin{tabular}{|c|c|c|}
\hline No. & Negara & $\begin{array}{l}\text { Target kandungan timbal } \\
\text { dalam cat kurun waktu 2012- } \\
2016\end{array}$ \\
\hline 1 & Nepal & maks. 90 ppm \\
\hline 2 & Bangladesh & maks. 50 ppm \\
\hline 3 & Srilanka & maks. 90 ppm \\
\hline 4 & India & maks. 90 ppm \\
\hline 5 & Philipina & maks. 90 ppm \\
\hline 6 & Thailand & $\begin{array}{l}\text { dalam tahap pengkajian dan } \\
\text { penyusunan regulasi }\end{array}$ \\
\hline 7 & Indonesia & $\begin{array}{l}\text { dalam tahap pengusulan } \\
\text { regulasi }\end{array}$ \\
\hline
\end{tabular}

Timbal dalam cat berasal dari penggunaan bahan baku penyusunan cat baik sebagai pigmen, bahan pengering, bahan anti korosi dan bahanbahan yang mengandung timbal sebagai pengotor (unintentional ingredients).
Pigmen yang mengandung timbal diantaranya adalah timbal (II) kromat $\left(\mathrm{PbCrO}_{4}\right)$ atau dikenal dengan nama Chrome Yellow, timbal oksida $\left(\mathrm{Pb}_{3} \mathrm{O}_{4}\right)$ atau red lead, dan timbal karbonat atau white lead.

Bahan pengering (dryer) merupakan senyawa kimia yang digunakan pada cat minyak (enamel) untuk menyempurnakan proses pembentukan lapisan cat kering. Dryer mengandung senyawa timbal diantaranya adalah timbal naftanat, timbal asetat, dan timbal oktoat.

Timbal oksida atau red lead dan senyawa timbal lainnya dapat digunakan sebagai inhibitor korosi dan meningkatkan fungsi perlindungan terhadap karat. Harga yang murah dan kualitas perlindungan yang cukup baik menjadi pertimbangan penggunaan bahan timbal oksida sebagai inhibitor korosi.

Senyawa timbal dalam cat dapat juga berasal dari pengotor yang terkandung dalam bahan-bahan penyusun cat seperti pengotor dalam bahan pengisi (filler), pewarna, dan aditif. Kandungan timbal yang terakumulasi secara tidak disengaja dan berasal dari bahan pengotor ini termasuk dalam kategori unintentional ingredients.

Berdasarkan sifat ikatan kimia unsur timbal dalam cat, pencemaran timbal dari produk cat dapat terjadi melalui mekanisme migrasi unsur atau melalui timbal terikat yang terkandung dalam produk cat tersebut. Pada mainan anak, baik yang diwarnai atau dilapisi dengan cat, persyaratan kandungan timbal dalam cat maksimum $90 \mathrm{mg} / \mathrm{kg}$ yang ditentukan berdasarkan mekanisme migrasi timbal dari material ke lingkungan. Analisanya mengguna-kan metode perendaman dengan $\mathrm{HCl}$ encer pada $\mathrm{pH}$ 1,5 selama 1 jam [5].

Kandungan timbal dalam cat dapat di analisa dengan menggunakan beberapa metode yaitu Chemical Test Kit, Flame Atomic Absorption Spectrometry (FAAS), Graphite Furnace Atomic Absorption Spectrometry (GFAAS), Inductively Coupled Plasma - Atomic Emission Spectrometry (ICP-AES) atau menggunakan X-Ray Fluorescence (XRF) [6].

Pada tahun 2014 Badan Standardisasi Nasional (BSN) menerbitkan SNI 3564:2014“Cat Tembok Emulsi” dan SNI 8011:2014, “Cat Dekoratif Berbasis Pelarut Organik" dengan melakukan pembatasan kandungan logam berbahaya termasuk timbal. Persyaratan kandungan timbal untuk cat tembok emulsi maksimum 90 ppm dan pada cat dekoratif 
berbasis pelarut organik maksimum 600 ppm. Lahirnya SNI ini merupakan salah satu langkah nyata dari pemerintah untuk mencegah dan mengurangi penggunaan bahan baku yang mengandung timbal di industri cat terutama untuk produk cat yang digunakan secara bebas oleh masyarakat umum atau cat domestik $[7,8]$.

Regulasi terkait produk cat domestik dan cat untuk keperluan industri (protective coating) seluruhnya masih bersifat sukarela atau belum diwajibkan. Pada tanggal 5 Juni 2015, BSN mengeluarkan pengumuman Program Nasional Regulasi Teknik (PNRT) tahun 2015-2016, salah satunya termasuk produk cat dengan judul "Cat Antifouling untuk Lambung Bawah Kapal Baja, Mutu dan Cara Uji”. Berdasarkan pengumuman tersebut, PNRT direncanakan untuk diberlakukan secara wajib dengan mengacu kepada revisi SNI 06-0502-1989. Untuk jenis cat yang lain belum ada rencana untuk diberlakukan secara wajib [9].

Produk cat sangat bervariasi dan dapat dikelompokkan menurut beberapa kategori atau tinjauan. Apabila ditinjau dari aspek material penyusunnya, produk cat dapat dikelompokkan menjadi cat jenis epoksi, alkyd, polyurethane, acrylic, chlorinated rubber, dan latex. Ditinjau dari aspek sifat kelarutannya, cat dapat dikelompokkan menjadi jenis cat berbasis air (water based) dan cat berbasis pelarut organik (solvent based). Dari aspek fungsi dikelompokkan menjadi jenis cat dekoratif (decorative coating) dan cat protektif (protective coating). Dan dari aspek pengguna atau keperluannya dapat dibagi menjadi cat untuk konsumen umum (domestik) dan cat untuk industri.

Menghilangkan timbal dalam cat tentu tidak semudah membalikkan telapak tangan. Pemerintah tentu tidak dapat begitu saja membuat regulasi yang ketat terkait pelarangan penggunaan timbal pada produk cat, tanpa mempertimbangkan berbagai dampak yang akan timbul pada aspek lain, seperti pertumbuhan ekonomi, perdagangan, kondisi masyarakat, dan kesiapan industri lokal baik industri besar maupun Industri Kecil Menengah (IKM).

Negara-negara maju yang melakukan inisiasi supaya penggunaan timbal dalam cat dihentikan di seluruh dunia pada tahun 2020 melalui diluncurkannya program Global Lead Paint Elimination by 2020. Persiapan tentu telah dilakukan di negara masing-masing sebelum memberi usulan.

Pemerintah Amerika Serikat misalnya, memulai langkah untuk mengurangi kandungan timbal dalam cat sejak tahun 1978 melalui regulasi yang dikeluarkan oleh U.S. Consumer Product Safety Comission (CPSC), 16 Code of Federal Regulation CFR part 1303. CFR ini berisi larangan penggunaan cat yang mengandung timbal di atas 0,06\% berat (600 ppm) tanpa menyebutkan metode uji yang harus digunakan. Revisi regulasi tersebut kemudian dilakukan pada tahun 2011 dengan menurunkan batas kandungan timbal menjadi maksimum $0,009 \%$ berat (90 ppm) [10]. Kurun waktu selama 33 tahun merupakan masa yang diperlukan pemerintah Amerika Serikat untuk mempersiapkan diri dalam mengeluarkan batasan kandungan timbal dalam cat sampai sebesar maksimum 90 ppm.

Indonesia dan negara-negara berkembang lainnya dituntut untuk melakukan pembatasan kandungan timbal dalam cat maksimum sebesar 90 ppm hanya dalam kurun waktu 5 tahun (20152020).

Kajian ini menjelaskan perkembangan program penghapusan cat dengan kandungan timbal di Indonesia dan tantangan industri cat nasional. Uji petik beberapa cat yang beredar di pasaran dilakukan untuk memperkuat diskusi. Makalah ini ditutup dengan uraian singkat beberapa langkah strategis dan teknis untuk menghadapi program penghilangan kandungan timbal pada produk cat pada tahun 2020.

\section{BAHAN DAN METODE}

Bahan yang dijadikan contoh uji terdiri dari 3 (tiga) produk cat tembok, 6 (enam) produk cat enamel, 1 (satu) produk cat antifouling, 1 (satu) produk cat alkyd, dan 1 (satu) produk cat marka jalan. Pengujian dilakukan pada Agustus 2015.

Pengujian dilakukan di Laboratorium Balai Besar Bahan dan Barang Teknik pada bulan Agustus 2015 dengan menggunakan metode AAS (Atomic Absorption Spectrometry). Alat yang digunakan adalah Flame-AAS, merek Perkin Elmer model Analyst 100.

Preparasi contoh dilakukan dengan metode acid digestion. Contoh cat basah dioleskan pada permukaan kaca transparan. Setelah kering, film (lapisan tipis) cat kering dikelupas dan dipotong kecil-kecil, kemudian ditimbang dengan ketelitian 0,1 mg. Film ditempatkan di dalam gelas kimia, dan direbus dengan $3 \mathrm{~mL} \mathrm{HNO}_{3}$ pekat dan $1 \mathrm{~mL} \mathrm{H}_{2} \mathrm{O}_{2} 30 \%$ di atas hot plate (api kecil) sampai sebagian besar asam menguap [1]. 
Perlakuan ini dilakukan dua kali. Gelas kimia berisi contoh dibilas dan diencerkan dengan aquadest dalam labu ukur untuk pengujian dengan AAS. Kurva kalibrasi AAS disajikan di Gambar 1.

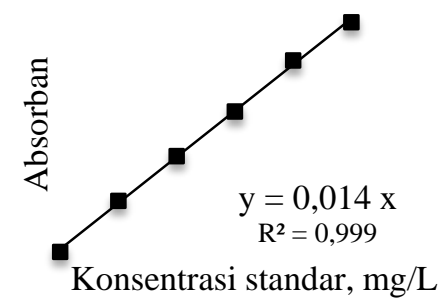

Gambar 1. Kurva Kalibrasi AAS Standar Pb

\section{HASIL DAN PEMBAHASAN}

Cat tembok ternyata memiliki kandungan timbal paling rendah dalam kisaran 10-48 mg/kg (Tabel 2). Cat ini memenuhi baku mutu nasional yaitu di bawah $90 \mathrm{mg} / \mathrm{kg}$ [7]. Cat enamel memiliki kandungan timbal pada kisaran 616$2254 \mathrm{mg} / \mathrm{kg}$ atau di atas persyartan $600 \mathrm{mg} / \mathrm{kg}$ [8]. Jadi, cat enamel tidak memenuhi persyaratan nasional.

Tabel 2. Hasil Pengujian Kandungan $\mathrm{Pb}$

\begin{tabular}{lclc}
\hline No. & $\begin{array}{l}\text { Kod } \\
\text { e }\end{array}$ & Keterangan untuk Cat & $\begin{array}{c}\text { Kandungan } \\
\text { Pb (mg/kg) }\end{array}$ \\
\hline 1 & A1 & Tembok warna abu-abu & 48 \\
2 & A2 & Tembok warna abu-abu & 26 \\
3 & A3 & Tembok warna merah muda & 10 \\
4 & B1 & Enamel warna biru & 757 \\
5 & B2 & Enamel warna hijau & 1385 \\
6 & B3 & Enamel warna hijau & 2159 \\
7 & B4 & Enamel warna hijau & 616 \\
8 & B5 & Enamel warna kuning & 1841 \\
9 & B6 & Enamel warna merah & 2254 \\
10 & C1 & Marka jalan warna kuning & 5876 \\
11 & C2 & Antifouling warna merah & 27 \\
& & tua & 50 \\
12 & C3 & Alkyd warna orange &
\end{tabular}

\section{Langkah-Langkah Teknis}

Produsen cat lokal (nasional) tentunya harus melakukan upaya-upaya untuk tidak lagi menggunakan bahan baku yang mengandung timbal pada produk yang dihasilkan. Beberapa industri cat besar seperti ICI, Pacific Paint, Propan, Jotun dan Mowilex, [11] sudah dapat menghasilkan produk cat yang ramah lingkungan dan mencantumkan logo bebas timbal pada kemasan produknya.
Jenis produk cat yang masih menggunakan senyawa timbal di atas baku mutu harus dihilangkan. Langkah abolisi atau penarikan terhadap Standar Nasional Indonesia (SNI) terkait produk cat jenis ini diharapkan dapat mendorong industri untuk berhenti memproduksi cat yang SNI nya diabolisi. SNI yang termasuk kategori ini diantaranya adalah SNI 06-3685.12000: Spesifikasi Cat Merah Timbal Siap Pakai, dengan kandungan timbal oksida $\left(\mathrm{Pb}_{3} \mathrm{O}_{4}\right)$ yang dipersyaratkan adalah minimum $65 \%$ berat [12], dan SNI 06-0063-1987: Mutu Cat Dasar Meni Timbal untuk Besi dan Baja dengan persyaratan kandungan timbal oksida $\left(\mathrm{Pb}_{3} \mathrm{O}_{4}\right)$ minimum $20 \%$ berat [13].

Sebagai bentuk dukungan teknis terhadap industri pengguna dan produsen, pemerintah dapat mendorong supaya lembaga-lembaga penelitian dan pengembangan, dan produsen bahan baku untuk bergerak cepat mencari bahan baku alternatif pengganti timbal oksida $\left(\mathrm{Pb}_{3} \mathrm{O}_{4}\right)$. Salah satu material yang memiliki potensi besar untuk dijadikan sebagai substitusi senyawa timbal adalah besi oksida $\left(\mathrm{Fe}_{3} \mathrm{O}_{4}\right)$ [14]. Besi oksida $\left(\mathrm{Fe}_{3} \mathrm{O}_{4}\right)$ dapat digunakan sebagai pigmen warna kuning, merah, cokelat dan hitam, tergantung valensinya. Selain itu, kromium oksida $\left(\mathrm{CrO}_{2}\right)$ dapat dijadikan sebagai pengganti pigmen warna biru, hijau, dan orange [16].

Sosialisasi teknis atau publikasi ilmiah tentang larangan penggunaan senyawa timbal sebagai bahan aditif juga perlu dilakukan, sehingga dapat mendorong pihak industri untuk melakukan langkah substitusi bahan baku. Senyawa organologam dari timbal $(P b)$ yang digunakan sebagai bahan aditif pengering (dryer) pada cat jenis enamel dapat diganti dengan senyawa organologam misalnya kobalt (Co) [3]. Kandungan timbal yang berasal dari pengotor atau unintentional yang secara tidak sengaja atau sadar terdapat dalam produk cat, dapat dihindari dengan cara meminta CoA(Certificate of Analysis), atau bukti teknis lainnya dari produsen bahan baku. Sertifikat ini harus menunjukkan bahwa bahan tersebut tidak mengandung senyawa timbal sebagai pengotor.

Bagi industri besar, substitusi senyawa $\mathrm{Pb}$ ini diperkirakan tidak akan mengalami kesulitan untuk menghasilkan cat bebas timbal. Dampak yang terjadi pada kenaikan harga dapat diimbangi dengan efisiensi di produksi, promosi dan merek. Industri Kecil Menengah (IKM) pada umumnya belum memiliki kemampuan riset dan 
pengembangan (R\&D) yang cukup untuk melakukan pengembangan produk. Perubahan pada spesifikasi produk, formulasi dan bahan baku, dikhawatirkan akan sangat menyulitkan pihak IKM. Pemerintah perlu melakukan upaya teknis yang dapat membantu IKM supaya dapat menghasilkan produk cat bebas timbal.

Pelatihan dan pendampingan teknis bagi IKM, akan sangat menolong IKM untuk tetap bertahan apabila regulasi pelarangan timbal pada tahun 2020 diterapkan. Pendampingan oleh lembaga Litbang pemerintah berupa bimbingan teknis dan formulasi dapat mempercepat adaptasi dan alih teknologi IKM tanpa menambah beban modal untuk melakukan riset.

\section{KESIMPULAN}

1. Kandungan timbal dalam cat tembok, cat antifouling, dan cat alkyd di Indonesia dapat memenuhi persyaratan SNI di bawah 90 $\mathrm{mg} / \mathrm{kg}$, yaitu berturut-turut 10-48 mg/kg, 27 $\mathrm{mg} / \mathrm{kg}$, dan $50 \mathrm{mg} / \mathrm{kg}$. Sedangkan kandungan timbal dalam cat enamel dan cat marka jalan melebihi $90 \mathrm{mg} / \mathrm{kg}$.

2. Rencana penghilangan timbal dalam produk melalui Global Lead Paint Elimination by 2020 perlu didukung oleh semua pihak terkait, untuk mengurangi resiko gangguan kesehatan dan membantu menjaga kelestarian lingkungan hidup.

3. Langkah yang bersifat strategis maupun teknis perlu dilakukan oleh pemerintah untuk mewujudkan rencana tersebut, diantaranya dengan melakukan pembenahan regulasi teknis, SNI, sosialisasi, publikasi ilmiah, memaksimalkan peran lembaga penelitian pemerintah, pelatihan dan pendampingan IKM.

\section{UCAPAN TERIMA KASIH}

Penulis mengucapkan terima kasih kepada Kepala Balai Besar Bahan dan Barang Teknik, serta Sdr. Indra Hadiwijaya dan Sdr. Jajuli yang telah membantu dalam penyusunan kajian ini.

\section{DAFTAR PUSTAKA}

[1] Yuyun Ismawati, dkk., 2013, Laporan Nasional Timbal dalam Cat Enamel Rumah Tangga di Indonesia, BalifokusIPEN.
[2] Suherni, 2010, Keracunan Timbal di Indonesia, LEAD Group Inc., Sydney Australia.

[3] Weinberg, J. \& Scott Clark, 2012, Global Lead Paint Elimination by 2020, "A test of the Effectiveness of the Strategic Approach to International Chemicals Management”, IPEN.org.

[4] IPEN, 2015, “Asian Lead Paint Elimination Project”, News Letter, Vol. 4, issue 1. http://ipen.org/sites/default/files/ documents,_diakses 20 January 202015.pdf

[5] SNI 12-6527.3-2001, "Keamanan Mainan, Bagian 3: Spesifikasi untuk Perpindahan Elemen-elemen Tertentu”, BSN.

[6] WHO - IOMC, 2011, "Brief Guide to Analytical Methods For Measuring Lead in Paint”, WHO Library Cataloguing-inPublication Data (www.who.int), ISBN 9789241502122.

[7] SNI 3564:2014, “Cat tembok Emulsi”, BSN.

[8] SNI 8011:2014, "Cat Dekoratif Berbasis Pelarut Organik”, BSN.

[9] Program Nasional Regulasi Teknis (PNRT) tahun 2015-2016, http:// www. bsn.go.id /uploads/download/ PNRT_2015 -20161.pdf, diakses10 Juni 2015, BSN.

[10] U.S. Consumer Product Safety Comission, "Ban of Lead-Containing Paint and Certain Consumer Products Bearing Lead", Containing Paint, 16 C.F.R 1303”, 2011, CPSC.

[11] http://properti.kompas.com/read/2009/09/0 7/08393813/Ini.Lho.Cara.Pilih.Cat.yang.A man, diakses 11 Juni 2015.

[12] SNI 06-3685.1-2000, "Spesifikasi Cat Merah Timbal Siap Pakai”, BSN.

[13] SNI 06-0063-1987, "Mutu Cat Dasar Meni Timbal untuk Besi dan Baja”, BSN.

[14] Taufiqurrahman, N., dkk. 2012, "Review Pengembangan Teknologi Pengolahan Sumber Daya Pasir Besi Menjadi Produk Bes/Baja, Pigmen, Bahan Keramik, Magnet, Kosmetik, Dan Fotokatalistik Dalam Mendukung Industri Nasional”, Prosiding InSINas, 2012.

[15] Yuyun Ismawati, dkk. , 2015, "Laporan Nasional Timbal dalam Cat Enamel Rumah Tangga di Indonesia”, BalifokusIPEN.

[16] Paint and Pigments, http://nzic.org.nz/ ChemProcesses/polymers/10D.pdf. diakses 11 Desember 2014. 